\title{
Caregivers of Patients with Heart Failure: Burden and the Determinants of Health-Related Quality of Life
}

\author{
Raquel Lahoz (1) \\ Clare Proudfoot ${ }^{2}$ \\ Ana Filipa Fonseca' \\ Emil Loefroth' \\ Stefano Corda ${ }^{3}$ \\ James Jackson (iD ${ }^{4}$ \\ Sarah Cotton $\mathbb{D}^{4}$ \\ Rachel Studer (D)
}

'Real World Evidence, Cardiovascular, Renal and Metabolism Franchise, Novartis Pharma AG, Basel, Switzerland; ${ }^{2}$ Health Economics and Outcomes Research, Cardiovascular, Renal and Metabolism Franchise, Novartis Pharma AG, Basel, Switzerland; ${ }^{3}$ Global Medical Affairs, Cardiovascular, Renal and Metabolism Franchise, Novartis Pharma AG, Basel, Switzerland; ${ }^{4}$ Real World Research, Adelphi Real World, Bollington, UK
Correspondence: Raquel Lahoz Real World Evidence and Data Science, Cardio-Renal-Metabolic Franchise, Novartis Pharma AG, Asklepios 8-4, Basel, $\mathrm{CH}-4002$, Switzerland

Tel +4I 795359930

Email raquel.lahoz@novartis.com
Purpose: To assess the burden among caregivers of patients with heart failure (HF) with left ventricular ejection fraction $(\mathrm{LVEF}) \leq 60 \%$. The burden by New York Heart Association (NYHA) functional class was also characterized.

Patients and Methods: A cross-sectional study was conducted in France, Germany, Italy, Spain, and UK from June to November 2019. Patient record forms were completed by 257 cardiologists and 158 general practitioners for consecutive HF patients. Caregivers who accompanied the patient to their consultation completed a caregiver self-completion survey voluntarily, which included the Family Caregiver Quality of Life Questionnaire (FAMQOL) and 5-level 5-dimension EuroQol questionnaire (EQ-5D-5L).

Results: We analyzed 361 caregivers of patients with HF (NYHA class I, n=41; II, n=212; III IV, $\mathrm{n}=108$ ). Mean age of caregivers was 58.8 years (NYHA I/II/III-IV: 59.1/60.8/54.6 years; $\mathrm{p}=0.0029)$, with majority being females $(73.1 \%)$. Caregivers spent on average 19.8 hours/week caring for a HF patient, which increased with increase in NYHA class (I/II/IIIIV: 11.8/18.1/25.9 hours/week; $p=0.0094)$. Caregivers (24.1\%) reported providing emotional support/encouragement to patients as the most troublesome/inconvenient caregiving activity (no significant difference across NYHA class). Nearly one-third of caregivers experienced stress (NYHA I/II/III-IV: 17.1\%/28.8\%/40.7\%; $\mathrm{p}=0.0111)$ and anxiety $(26.8 \% / 24.1 \% /$ $39.8 \%$; $=0.0127$ ) due to caregiving burden. The overall FAMQOL mean score decreased significantly (poorer QoL) with increase in NYHA class (I/II/III-IV: 58.1/56.3/52.2; $\mathrm{p}=0.0069$ ). A trend of decreasing scores with increasing NYHA class was observed across physical, emotional, and social domains (each $\mathrm{p} \leq 0.012$ ).

Conclusion: Caregivers of HF patients with LVEF $\leq 60 \%$ experienced a significant burden, which was higher among caregivers of patients with more severe and symptomatic disease.

Keywords: burden, caregiver, heart failure, NYHA class, quality of life, real world evidence

\section{Introduction}

Heart failure (HF) is a chronic disease affecting about 40 million people globally. ${ }^{1}$ A reported 15 million people are affected with HF in Europe, ${ }^{2}$ and HF prevalence is increasing as the population ages. ${ }^{3} \mathrm{HF}$ is a public health problem with a high burden on patients and healthcare system costs, mainly driven by frequent hospitalizations, poor health-related quality of life (HRQoL), and high mortality rates despite available and recommended treatments. 4,5

The impact of HF is not limited to patients but also extends to their families. Patients with HF experience symptoms (examples shortness of breath, chest pain, 
weakness, sleeping problems, depression) that limit their physical and social activities. ${ }^{6}$ Approximately $75 \%$ of patients with HF have difficulties in performing their daily activities, ${ }^{7}$ compelling them to rely on family and other informal caregivers to perform these activities. Family and friends play a central role in the care of these patients and are regularly required to provide care for their loved ones. ${ }^{6,8}$

Being a caregiver for a patient with HF is a strenuous task. Previous studies demonstrated that these caregivers experienced reduced HRQoL, and caregiving had a negative impact on their physical and emotional health. ${ }^{9,10}$ Caregiving to patients with $\mathrm{HF}$ also had an impact on the social life and employment of the caregiver and was associated with economic burden. ${ }^{11,12}$

Based on the left ventricular ejection fraction (LVEF), which is the percentage of blood being pumped out of the left ventricle with each contraction, HF is classified into three subtypes-HF with reduced ejection fraction (HFrEF, LVEF $<40 \%$ ), HF with mid-range ejection fraction (HFmrEF, LVEF 40-49\%), and HF with preserved ejection fraction (HFpEF, LVEF $\geq 50 \%$ ). ${ }^{13} \mathrm{HFrEF}$ accounts for $50 \%$ of cases, with HFmrEF/HFpEF accounting for the remaining 50\%. ${ }^{14}$ Although the proportion of patients with HFrEF and HFmrEF/HFpEF is reported to be similar, the patient- or caregiver-reported burden of HF has been primarily studied in HFrEF. ${ }^{15}$ Several therapies have shown clinical benefits in $\mathrm{HFrEF} ;{ }^{13}$ however, to date, no therapies have been approved for HFpEF. A few clinical studies have shown some indication of benefit in patients with higher LVEF (patients with LVEF $>40 \%$ in CHARMPRESERVED $^{16}$ and $\geq 45 \%$ in PARAGON-HF ${ }^{17}$ and TOPCAT $^{18}$ ), typically with the treatment effect attenuating as LVEF increases towards normal population LVEF levels. The burden of disease in patients with HF and their caregivers has not been entirely characterized, especially in the total HF population with a subnormal LVEF, which represents the total population who may be able to benefit from currently available pharmacotherapies.

The severity of HF is categorized based on the New York Heart Association (NYHA) functional class, which increases in severity from class I ("no limitation in physical activity") to IV ("unable to perform physical activity"). ${ }^{19}$ Patient burden of HF has been shown to increase with an increase in the NYHA class. ${ }^{20}$ However, research characterizing the burden of HF among caregivers and how it relates to the severity of HF is limited. The present study aimed to assess the burden on caregivers of patients with HF with subnormal LVEF $(\leq 60 \%)$ in a real-world setting in major countries from Europe. We also aimed to explore whether differences existed in burden among caregivers caring for patients with HF in different classes of NYHA.

\section{Patients and Methods Study Design}

The Adelphi Disease Specific Programme (DSPTM) is a large multinational survey conducted in clinical practice to characterize the burden of a disease from physician, patient, and caregiver perspectives. The DSPTM methodology has been published in detail previously. ${ }^{21-23}$

This was a cross-sectional survey of patients with HF and their informal caregivers conducted in a real-world setting in France, Germany, Italy, Spain, and the United Kingdom between June and November 2019. The study comprised four questionnaires: a physician survey, a patient record form, a patient self-completion questionnaire, and a caregiver self-completion questionnaire. Physicians (cardiologists and general practitioners [GPs]) who were contacted for interviews completed the patient record forms for consecutively consulting patients with HF. The same patients were invited to complete a selfcompletion questionnaire, and their informal caregiver a caregiver self-completion questionnaire. Patients did not have to complete their self-completion questionnaire for their caregiver to be able to complete the caregiver self-completion questionnaire. Patients completing the self-completion questionnaire were adults $(\geq 18$ years old), had a confirmed diagnosis of HF, and were not involved in any clinical trials of HF intervention.

The study was conducted in accordance with the ethical principles originating in the Declaration of Helsinki. Since this study involved the participation of human subjects, the protocol was submitted to the Western International Review Board (study protocol number 8649), but the ethical approval was not necessary and a waiver was provided because the study aimed to improve understanding rather than testing hypotheses. Informed consents were obtained from physicians, patients, and caregivers before the start of study.

\section{Study Measures}

Data collected in patient record forms and patient selfcompletion questionnaires comprised symptoms of HF, severity of HF, time since diagnosis of HF, and comorbidities. Information collected in the caregiver self- 
completion questionnaire included demographics, awareness of patients' and own health, caregiving activities/ responsibilities, time spent on caregiving, impact of caregiving on caregivers' own health, and emotional and financial burden of HF caregiving.

Disruption to caregivers' everyday life and impact on health were measured on a scale of 1 ("no disruption/ impact at all") to 10 ("severe disruption/impact"). HRQoL was measured using the Family Caregiver Quality of Life Questionnaire (FAMQOL) ${ }^{24}$ and the 5-level 5-dimension EuroQol questionnaire (EQ-5D$5 \mathrm{~L}){ }^{25,26}$ FAMQOL is a caregiver-specific questionnaire comprising 16 items rated on a 5-point Likert scale, with responses ranging from "strongly disagree" to "strongly agree". ${ }^{24}$ It measures the family caregivers" perception of their own well-being owing to HF caregiving on four domains: physical, psychological, social, and spiritual. The total score for each domain can vary between 4 and 20, with an overall total score ranging from 16 to 80 . A higher score indicates a better QoL. ${ }^{24}$ EQ-5D is a widely used generic instrument consisting of a 5-question descriptive system (EQ-5D index) and a 100-point visual analogue scale (EQ-5D VAS), with a descriptive system measuring five dimensions of health (mobility, self-care, usual activities, pain/discomfort, and anxiety/depression) at five levels (no, slight, moderate, severe, and extreme problems). ${ }^{25,26}$ In line with the National Institute for Health and Care Excellence (NICE) guidelines, the EQ-5D-5L scores were cross-walked to EQ-5D-3L scores. ${ }^{27}$ The financial burden on caregivers included direct/indirect costs due to HF caregiving.

\section{Data Analysis}

After the survey, anonymized data were received and analyzed on the aggregated sample. The physicians were assigned a number to allow linking of results between physician, patient, and caregiver questionnaires. Descriptive statistics were reported as frequency and/or percentages for categorical variables and mean, standard deviation (SD), median, range, and first and third quartiles for continuous variables. All variables were analyzed by the NYHA functional classes I, II, and III-IV. As the sample size of caregivers for patients with NYHA class IV was only 10 and was considered too small to provide meaningful conclusions, the data for NYHA classes III and IV were combined. Fisher's Exact, Mann-Whitney, and Pearson's Chi-square tests were used to demonstrate differences between the groups based on the NYHA class. Data for missing values were not imputed. All data were analyzed using UNICOM Intelligence Reporter version 7.5 or later, a database creation software (IBM SPSS Statistics v.25). A value of $p<0.05$ was considered significant.

\section{Results}

Figure 1 depicts the flow of participants in the study. Fourhundred and fifteen physicians completed patient record forms for 3316 patients with HF. Of these, 2479 patients had a current LVEF $\leq 60 \%$. In total, 361 caregivers of HF patients with $\mathrm{LVEF} \leq 60 \%$ completed the voluntary caregiver self-completion questionnaire. Caregivers completing the self-completion questionnaire were distributed unevenly across the participating countries (Germany, 158; United Kingdom, 72; France, 50; Spain, 49; Italy, 32).

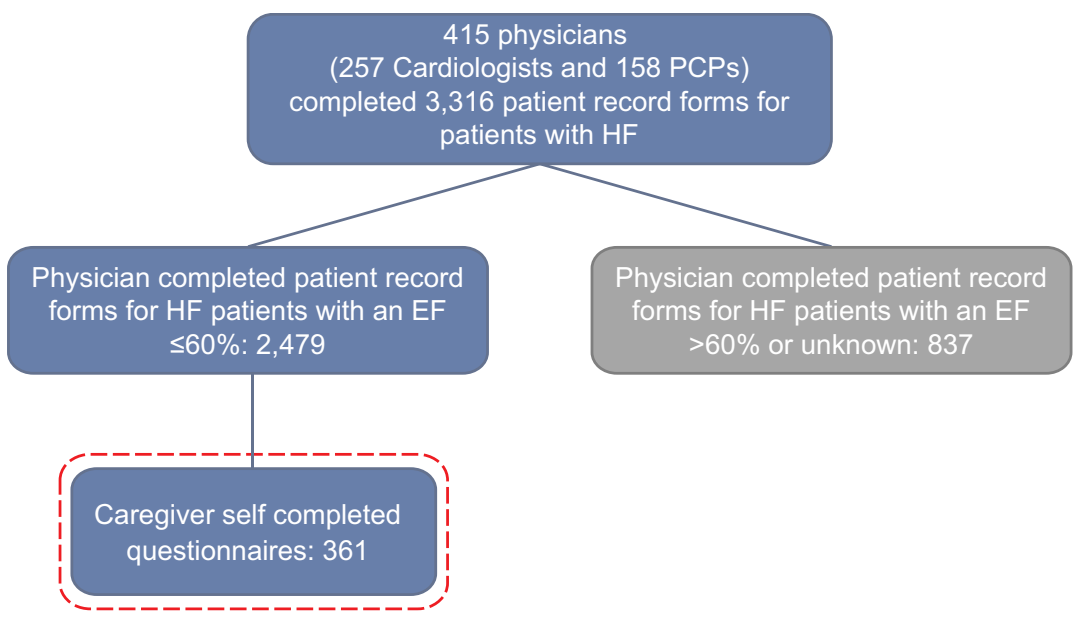

Figure I Study participants flow chart. 
The mean age of patients with linked caregiver data available was 71.2 years, and $60.1 \%$ of the patients were male; $11.4 \%(\mathrm{n}=41)$ were in NYHA class $\mathrm{I}, 58.7 \%(\mathrm{n}=212)$ in class II, and $29.9 \%(n=108)$ in class III-IV. Patients in NYHA classes III-IV were older than those in NYHA class I/ II (74.0 vs $67.3 / 70.5$ years; $p=0.0007)$. The common comorbidities among these patients were hypertension (54.0\%), hyperlipidaemia (35.7\%), atrial fibrillation (23.4\%), depression $(17.5 \%)$, and anxiety (17.2\%). The proportion of patients with each comorbidity was higher with an increase in the NYHA class; however, this trend was statistically significant only for atrial fibrillation, depression, and anxiety.

\section{Caregiver Demographics}

Of the 361 caregivers of patients with HF who responded, $73 \%$ were female, with a mean (SD) age of 58.8 (14.4) years. Caregivers of patients in NYHA classes III-IV were younger compared with caregivers of patients in NYHA class I/II (54.6 vs 59.1/60.8 years; $p=0.0029)$. Caregivers were most commonly spouses/partners $(58.2 \%)$ or a son/ daughter $(23.4 \%)$ to the patients. Compared with patients in a lower NYHA class, patients in a higher NYHA class were less frequently taken care of by their spouses/partners and more frequently by their son/daughter (Table 1).

\section{Burden on Caregivers of Patients with HF Time Spent on Caregiving}

Caregivers $(n=335)$ had cared for patients with HF for a mean (SD) duration of 3.0 (4.0) years; the duration was higher with an increase in the NYHA class (I, $\mathrm{n}=38: 2.6$ [3.3] years; II, $n=199: 2.9$ [4.0] years; III-IV, $n=98: 3.6$ [4.0] years; $\mathrm{p}=0.2962)$. Caregivers $(\mathrm{n}=317)$ spent on average 19.8

Table I Caregiver Demographics

\begin{tabular}{|c|c|c|c|c|c|}
\hline & \multirow[t]{2}{*}{ Overall $(\mathrm{N}=36 \mathrm{I})$} & \multicolumn{4}{|c|}{ By NYHA Class ${ }^{\#}$} \\
\hline & & NYHA I $(n=4 I)$ & NYHA II $(n=2 \mid 2)$ & NYHA III-IV $(n=108)$ & P-value \\
\hline Age (years), mean (SD) & $58.8(14.4)$ & $59.1(13.0)$ & $60.8(13.5)$ & $54.6(15.7)$ & 0.0029 \\
\hline Female gender, n (\%) & $264(73.1)$ & $29(70.7)$ & $159(75.0)$ & $76(70.4)$ & 0.6326 \\
\hline $\begin{array}{l}\text { Marital status, n (\%) } \\
\text { Married } \\
\text { Single } \\
\text { Divorced } \\
\text { Widowed }\end{array}$ & $\begin{array}{c}N=356 \\
292(82.0) \\
44(12.4) \\
\text { II (3.I) } \\
9(2.5)\end{array}$ & $\begin{array}{c}n=40 \\
35(87.5) \\
4(10.0) \\
I(2.5) \\
0\end{array}$ & $\begin{array}{c}\mathrm{n}=208 \\
170(81.7) \\
24(11.5) \\
9(4.3) \\
5(2.4)\end{array}$ & $\begin{aligned} n & =108 \\
87 & (80.6) \\
16 & (14.8) \\
1 & (0.9) \\
4 & (3.7)\end{aligned}$ & 0.503 \\
\hline $\begin{array}{l}\text { Relationship to the patient, } \mathbf{n} \text { (\%) } \\
\text { Husband/wife/partner } \\
\text { Son/daughter } \\
\text { Professional caregiver } \\
\text { Grandson/granddaughter } \\
\text { Friend/neighbour } \\
\text { Brother/sister } \\
\text { Other relative }\end{array}$ & $\begin{array}{c}\mathrm{N}=359 \\
209(58.2) \\
84(23.4) \\
16(4.5) \\
15(4.2) \\
10(2.8) \\
6(1.7) \\
19(5.3)\end{array}$ & $\begin{array}{c}n=4 \mid \\
28(68.3) \\
6(14.6) \\
3(7.3) \\
2(4.9) \\
0 \\
I(2.4) \\
I(2.4)\end{array}$ & $\begin{array}{c}n=210 \\
134(63.8) \\
43(20.5) \\
5(2.4) \\
4(1.9) \\
5(2.4) \\
3(1.4) \\
16(7.6)\end{array}$ & $\begin{array}{c}\mathrm{n}=108 \\
47(43.5) \\
35(32.4) \\
8(7.4) \\
9(8.3) \\
5(4.6) \\
2(1.9) \\
2(1.9)\end{array}$ & 0.0015 \\
\hline $\begin{array}{l}\text { Employment status, } \mathbf{n}(\%) \\
\text { Retired } \\
\text { Working full time } \\
\text { Homemaker } \\
\text { Working part time } \\
\text { Unemployed } \\
\text { Student } \\
\text { On long-term sick leave }\end{array}$ & $\begin{array}{l}154(42.7) \\
81(22.4) \\
54(15.0) \\
44(12.2) \\
23(6.4) \\
4(1.1) \\
1(0.3)\end{array}$ & $\begin{array}{c}20(48.8) \\
9(22.0) \\
5(12.2) \\
4(9.8) \\
3(7.3) \\
0 \\
0\end{array}$ & $\begin{array}{l}98(46.2) \\
39(18.4) \\
37(17.5) \\
21(9.9) \\
14(6.6) \\
2(0.9) \\
1(0.5)\end{array}$ & $\begin{array}{c}36(33.3) \\
33(30.6) \\
12(11.1) \\
19(17.6) \\
6(5.56) \\
2(1.9) \\
0\end{array}$ & 0.2052 \\
\hline $\begin{array}{l}\text { Is patient's main caregiver, } \mathbf{n}(\%) \\
\text { Yes }\end{array}$ & $\begin{array}{c}N=338 \\
317(93.8)\end{array}$ & $\begin{array}{c}n=38 \\
36(94.7)\end{array}$ & $\begin{array}{c}n=199 \\
193(97.0)\end{array}$ & $\begin{array}{c}n=101 \\
88(87.1)\end{array}$ & 0.0036 \\
\hline
\end{tabular}

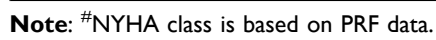

Abbreviations: NYHA, New York Heart Association; PRF, patient record form; SD, standard deviation. 
hours/week caring for patients with HF, which increased significantly with higher NYHA class (I, $\mathrm{n}=33$ : 11.8; II, $\mathrm{n}=186$ : 18.1; III-IV, $\mathrm{n}=98: 25.9$ hours/week; $\mathrm{p}=0.0094$ ).

\section{Caregiving Activities/Responsibilities}

Caregivers reported that the most common caregiving activities given to patients with HF were providing emotional support/encouragement (79\%), reminding the patient to take their medicine $(66 \%)$, helping with shopping (58\%), and driving the patient to work/hospital/ appointments (56\%; Figure 2A). When asked about the activities that are most troublesome/inconvenient to them, caregivers mentioned providing emotional support/encouragement (24\%), driving the patient to work/hospital/ appointments (13\%), reminding patients to take their medicine $(12 \%)$, and helping the patient for physical exercise $(9 \%)$. A trend of increase in caregiving activities such as driving the patient to work/hospital/appointments,

\section{A}

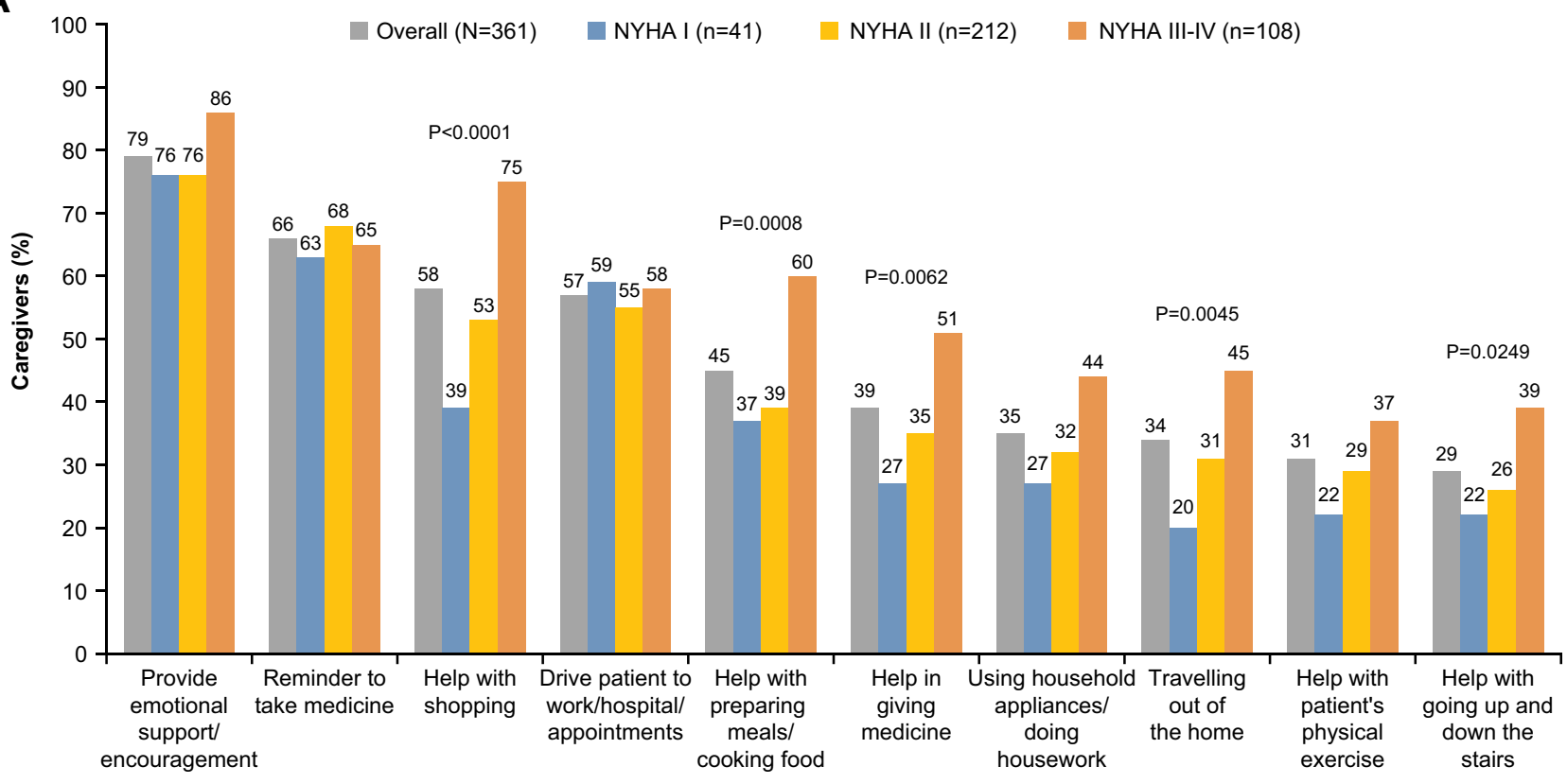

B

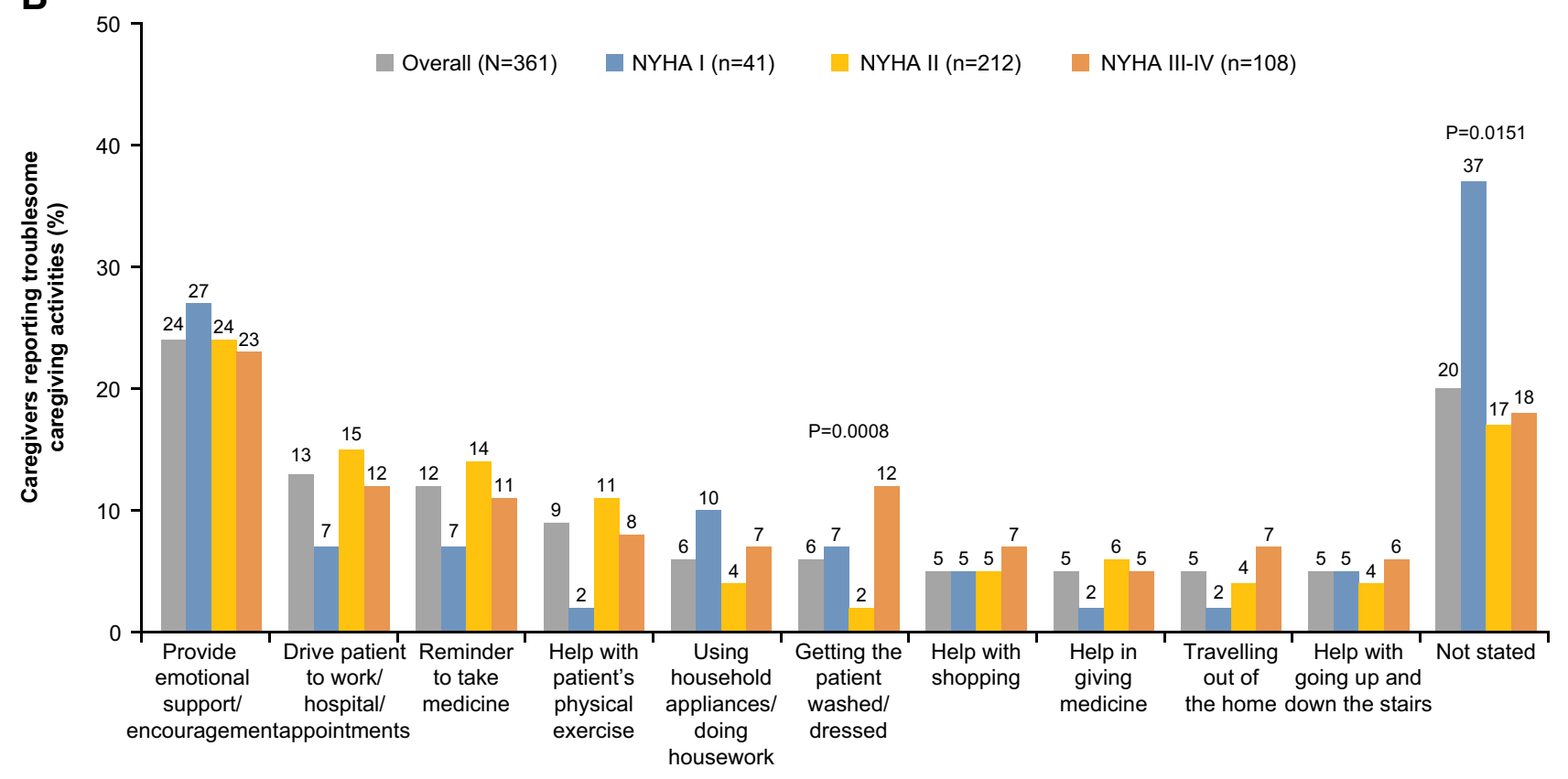

Figure 2 Caregivers reported: (A) Top 10 caregiving activities. (B) Top 10 most troublesome/inconvenient caregiving activities. 
reminder to take medicines, and helping with patient's physical exercise was observed with an increase in the NYHA class of patients with HF (Figure 2B).

\section{Impact on Caregivers' Daily Life and Health}

On a scale from 1 (no disruption) to 10 (severe disruption), caregivers reported a median score of 4.0 (interquartile range [IQR]: 2.0-6.0) to indicate the level of disruption in their everyday life due to HF caregiving. The disruption to caregivers' daily life was significantly higher $(p<0.0001)$ with an increase in the NYHA class of patients with HF (Figure 3A). Likewise, for the impact on caregivers' own health due to HF caregiving, caregivers provided a median score of 3.0 (IQR: 2.0-6.0) on a scale of 1 (no impact) to 10 (severe impact), which increased significantly $(\mathrm{p}=0.0023)$ with an increase in the NYHA class (Figure 3B).

Regarding the problems experienced/exacerbated owing to HF caregiving, all problems (apart from headaches) were experienced by a higher proportion of caregivers as the NYHA class increased. Approximately one-third of the caregivers experienced psychological problems due to caregiving

burden, including stress (31\%) and anxiety (29\%). There was a significantly greater impact on caregivers of patients with worse disease severity (stress, anxiety; $\mathrm{p}=0.01$; Figure 4).

\section{Impact on Caregivers' HRQoL}

\section{Family Caregiver-Specific QoL (FAMQOL) Scores}

The overall median FAMQOL score was 55.3 (IQR: 47.0-64.0), which decreased significantly (poorer HRQoL) with an increase in the NYHA class of patients $(p=0.0069)$. A significant decrease in scores with increase in severity of HF by NYHA class was observed across physical, emotional, and social domains (Table 2).

\section{EQ-5D Scores}

The mean EQ-5D utility scores were similar across NYHA classes. EQ-5D VAS scores showed a decreasing trend with increasing NYHA class, but differences were not statistically significant. The mean EQ-5D index score was 0.90 and EQ-5D VAS score was 76.6 (Table 2), showing a relatively high health-related utility for caregivers.
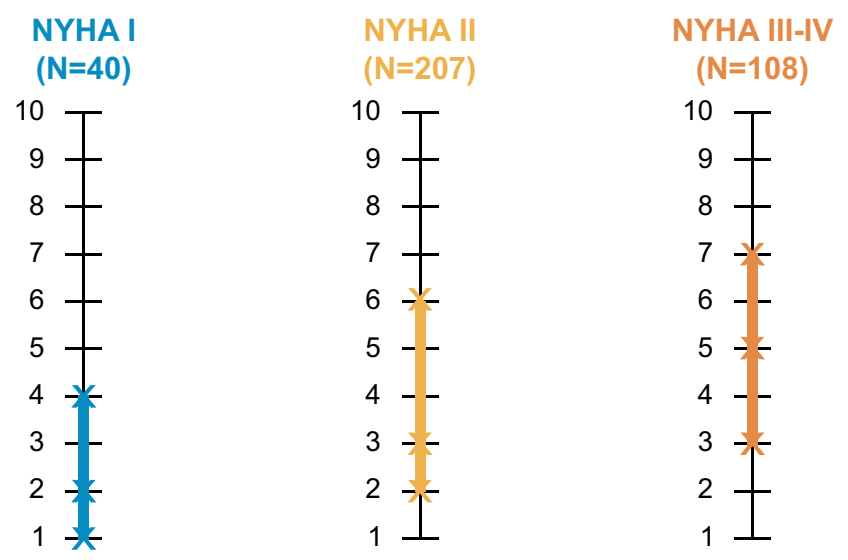

B

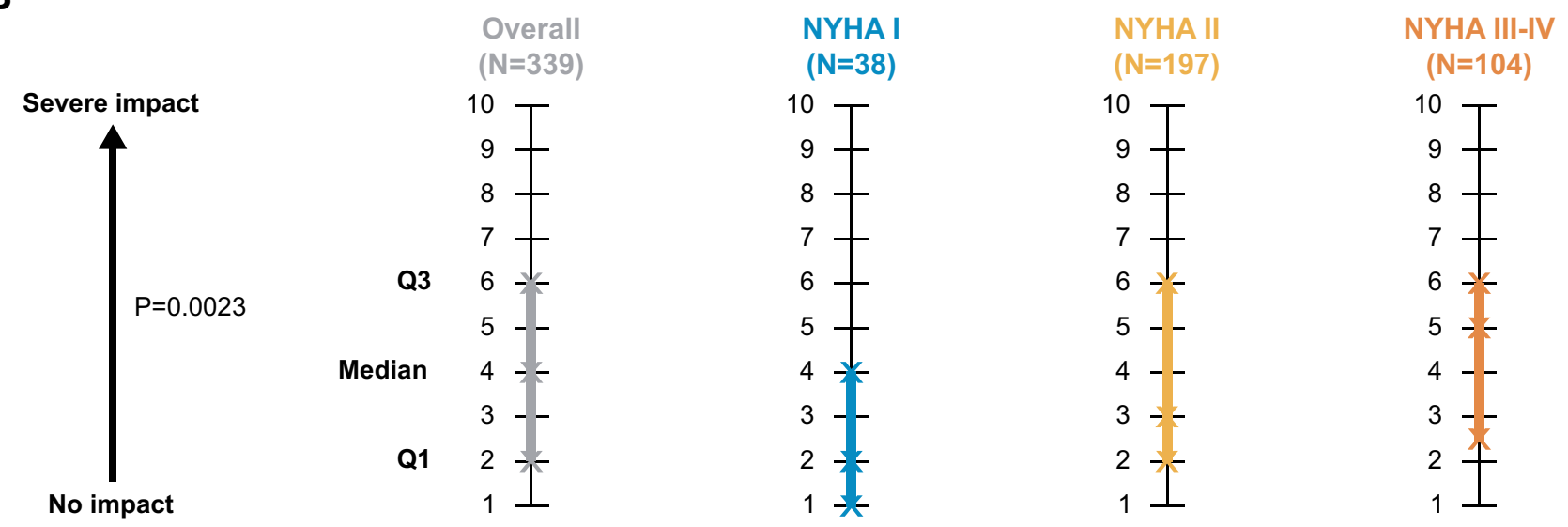

Figure 3 Caregivers reported scores to indicate: (A) Disruption in caregivers' everyday life. (B) Impact on caregivers' own health. 


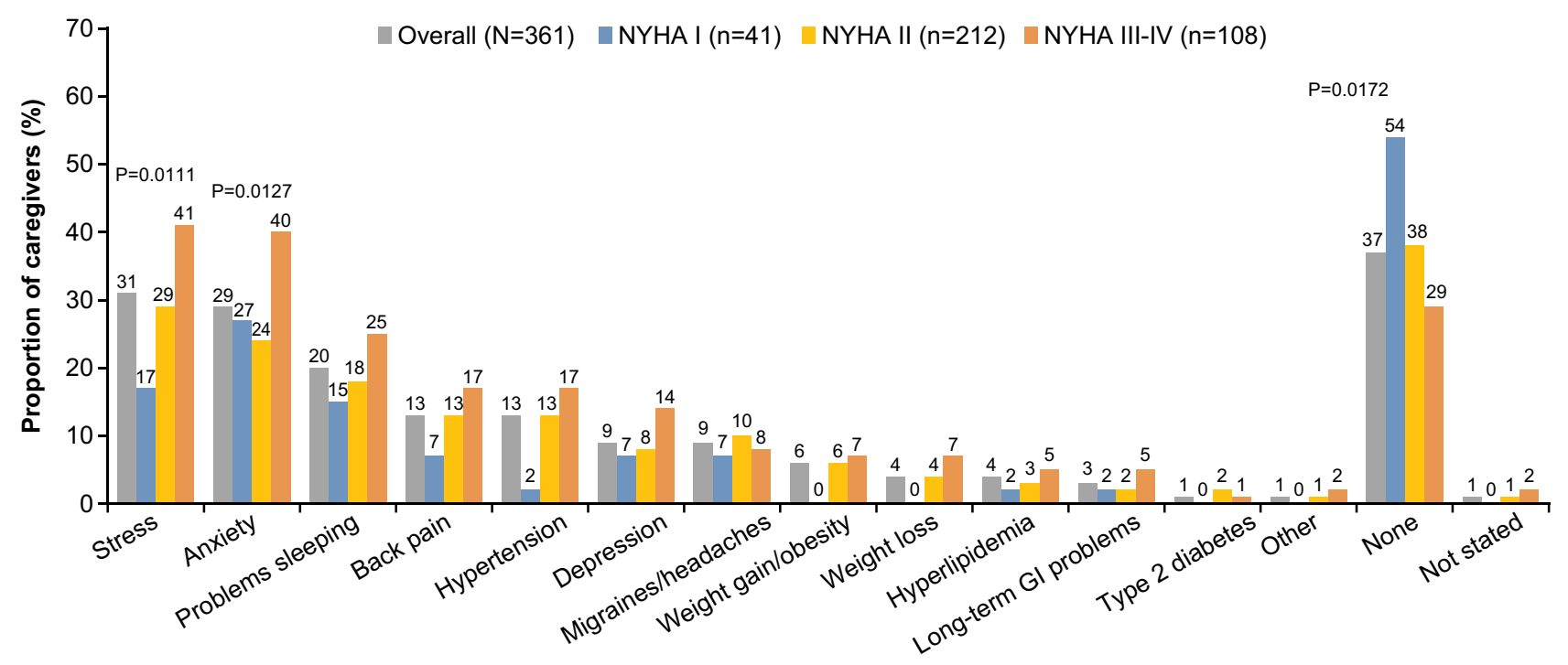

Figure 4 Caregivers reported health problems experienced or exacerbated due to HF caregiving.

\section{Impact on Caregivers' Employment}

A shown in Table 1, approximately $35 \%(n=125)$ of caregivers were in full-time or part-time employment, $15 \%$ were homemakers, and $43 \%$ were retired. Approximately $22.4 \%$ of the employed caregivers reported a change in their work in the last year due to HF caregiving activities. A high proportion of caregivers who were in full-time or part-time employment reported that they took absence from work: $73.6 \%$ had taken paid leave and $60.8 \%$ unpaid leave to manage their caregiving responsibilities. Information on drop in income was available from a limited number of caregivers $(\mathrm{n}=25)$, with $80 \%$ of them reporting a drop in income due to HF caregiving. There was no significant trend observed for the impact on employment by NYHA class (Table 3).

\section{Financial Burden on Caregivers}

Regarding the cost of HF, the healthcare system mostly paid for the patient-related costs, and a majority of the

Table 2 Health-Related Quality of Life of Caregivers of Patients with HF

\begin{tabular}{|c|c|c|c|c|c|}
\hline Scale & Overall $(\mathrm{N}=36 \mathrm{I})$ & NYHA I $(n=4 I)$ & NYHA II $(n=2 \mid 2)$ & NYHA III-IV $(n=\mid 08)$ & P-value \\
\hline \multicolumn{6}{|c|}{ FAMQOL scale" } \\
\hline Overall score & $N=342$ & $n=38$ & $\mathrm{n}=204$ & $n=100$ & 0.0069 \\
\hline Mean & $55.3(11.4)$ & $58.1(13.8)$ & $56.3(10.8)$ & $52.2(11.0)$ & \\
\hline Physical score & $N=35 I$ & $\mathrm{n}=40$ & $n=206$ & $\mathrm{n}=105$ & 0.0007 \\
\hline Mean & $14.6(3.2)$ & $15.6(3.1)$ & I4.8 (3.2) & I3.7 (3.1) & \\
\hline Emotional score & $N=354$ & $n=40$ & $\mathrm{n}=209$ & $\mathrm{n}=105$ & 0.012 \\
\hline Mean & $13.4(4.1)$ & $15.0(4.6)$ & I $3.4(4.0)$ & $12.8(4.1)$ & \\
\hline Social score & $N=349$ & $n=38$ & $n=209$ & $n=102$ & 0.0003 \\
\hline Mean & 14.7 (3.7) & 15.0 & $15.2(3.6)$ & I3.5 (3.5) & \\
\hline \multicolumn{6}{|l|}{ EQ-5D-5L scale } \\
\hline Utility score* & $N=360$ & $n=40$ & $n=212$ & $n=108$ & 0.8578 \\
\hline Mean (SD) & $0.90(0.12)$ & $0.89(0.13)$ & $0.90(0.12)$ & $0.89(0.12)$ & \\
\hline VAS score ${ }^{* *}$ & $N=359$ & $n=40$ & $n=211$ & $n=108$ & 0.5058 \\
\hline Mean & $76.6(14.7)$ & 79.8 (13.7) & 76.4 (I4.I) & $75.9(16.0)$ & \\
\hline
\end{tabular}

Notes: *EQ-5D-5L: Scores range from less than 0 (where $0=$ health state equivalent to death; negative values valued as worse than death) to I (perfect health). **EQ-5D VAS: Scale of 0-100, where $0=$ worst imaginable health and $100=$ best imaginable health. ${ }^{*}$ Family Caregiver-Specific Quality of Life Scale: Overall: Possible range of $16-80$, with 80 representing higher family caregiver-specific QoL; Physical, Emotional, Social: Possible range of 4-20, with 20 representing higher well-being.

Abbreviations: NYHA, New York Heart Association; PRF, patient record form; SD, standard deviation. 
Table 3 Impact of HF Caregiving on Employment and Financial Burden

\begin{tabular}{|c|c|c|c|c|c|}
\hline & $\begin{array}{l}\text { Overall } \\
(N=36 I)\end{array}$ & $\begin{array}{l}\text { NYHA } \\
\text { I (n=4I) }\end{array}$ & $\begin{array}{l}\text { NYHA II } \\
(n=2 \mid 2)\end{array}$ & $\begin{array}{l}\text { NYHA III-IV } \\
\qquad(n=108)\end{array}$ & P-value \\
\hline \multicolumn{6}{|l|}{ Impact on employment } \\
\hline \multicolumn{6}{|l|}{$\begin{array}{l}\text { Impact on work as a result of caregiving activities ( } 12 \\
\text { months), } \mathbf{n}(\%)\end{array}$} \\
\hline Reduced the number of work hours/days & $23(6.4)$ & $3(7.3)$ & $13(6.1)$ & $7(6.5)$ & 0.9589 \\
\hline Changed role/position in current job & $4(1.1)$ & I (2.4) & $2(0.9)$ & $\mathrm{I}(0.9)$ & 0.688 \\
\hline Changed the job & I (0.3) & 0 & 0 & I (0.9) & 0.309 \\
\hline None of the above & $276(76.5)$ & $32(78.1)$ & $162(76.4)$ & $82(75.9)$ & 0.9633 \\
\hline Not stated & $59(16.3)$ & $6(14.6)$ & $35(16.5)$ & $18(16.7)$ & 0.9512 \\
\hline Absence from work, $n$ (\%) & $N=125$ & $n=13$ & $n=60$ & $\mathrm{n}=52$ & \\
\hline Paid days off due to caregiving responsibilities & $92(73.6)$ & $(69.2)$ & $43(71.7)$ & $40(76.9)$ & 0.7639 \\
\hline Unpaid days off due to caregiving responsibilities & $76(60.8)$ & $8(6 \mid .5)$ & $34(56.7)$ & $34(65.4)$ & 0.6403 \\
\hline I have not worked in the last 3 months & $9(7.2)$ & I (7.7) & $4(6.7)$ & $4(7.7)$ & 0.9757 \\
\hline Not stated & $14(1 \mid .2)$ & $3(23.1)$ & $8(13.3)$ & $3(5.8)$ & 0.1604 \\
\hline $\begin{array}{l}\text { Had a drop in income, } \mathbf{n}(\%) \\
\text { Yes } \\
\text { No }\end{array}$ & $\begin{array}{c}N=25 \\
20(80.0) \\
5(20.0)\end{array}$ & $\begin{array}{c}n=2 \\
2(100) \\
0\end{array}$ & $\begin{array}{l}n=15 \\
11(73.3) \\
4(26.7)\end{array}$ & $\begin{array}{c}n=8 \\
7(87.5) \\
I(12.5)\end{array}$ & 0.5494 \\
\hline \multicolumn{6}{|l|}{ Financial burden } \\
\hline $\begin{array}{l}\text { Receive financial assistance from the healthcare system or } \\
\text { social services, } \mathbf{n}(\%)\end{array}$ & $\mathrm{N}=28 \mathrm{I}$ & $n=28$ & $n=169$ & $n=84$ & 0.4731 \\
\hline Yes & $44(15.7)$ & $4(14.3)$ & $30(17.8)$ & $10(11.9)$ & \\
\hline No & $237(84.3)$ & $24(85.7)$ & $139(82.3)$ & $74(88.1)$ & \\
\hline $\begin{array}{l}\text { Responsible for paying for patient's HF medication, } \mathbf{n}(\%) \\
\text { No } \\
\text { Prescription medicine }\end{array}$ & $\begin{aligned} N & =348 \\
291 & (83.6) \\
16 & (4.6)\end{aligned}$ & $\begin{aligned} n & =40 \\
37 & (92.5) \\
I & (2.5)\end{aligned}$ & $\begin{array}{l}n=206 \\
167(81.1) \\
10(4.9)\end{array}$ & $\begin{aligned} n & =102 \\
87 & (85.3) \\
5 & (4.9)\end{aligned}$ & 0.43 \\
\hline $\begin{array}{l}\text { Responsible for paying for patient's HF-related } \\
\text { rehabilitation costs, } \mathbf{n}(\%) \\
\text { No } \\
\text { Yes, some of the cost }\end{array}$ & $\begin{array}{l}N=349 \\
307(88.0) \\
2(0.6)\end{array}$ & $\begin{array}{c}n=40 \\
38(95.0) \\
0\end{array}$ & $\begin{array}{l}n=207 \\
180(87.0) \\
I(0.5)\end{array}$ & $\begin{array}{l}n=102 \\
89(87.3) \\
1(1.0)\end{array}$ & 0.6461 \\
\hline $\begin{array}{l}\text { Responsible for paying for patient's HF-related } \\
\text { hospitalizations, } \mathbf{n}(\%)\end{array}$ & $N=350$ & $n=40$ & $\mathrm{n}=207$ & $n=103$ & 0.4957 \\
\hline No & $303(86.6)$ & $37(92.5)$ & $175(84.5)$ & $91(88.4)$ & \\
\hline Yes, all of the cost & $\mathrm{I}(0.3)$ & 0 & 0 & I (I.0) & \\
\hline Yes, some of the cost & $\mathrm{I}(0.3)$ & 0 & I (0.5) & 0 & \\
\hline $\begin{array}{l}\text { Responsible for paying HF-related travel costs for self and/ } \\
\text { or the patient, } \mathbf{n}(\%)\end{array}$ & $\mathbf{N}=349$ & $n=40$ & $\mathrm{n}=\mathbf{2 0 7}$ & $n=102$ & 0.6884 \\
\hline No & $306(87.7)$ & $35(87.5)$ & $183(88.4)$ & $88(86.3)$ & \\
\hline Yes, all of the cost & $35(10.0)$ & $4(10.0)$ & I8 (8.7) & $13(12.8)$ & \\
\hline Yes, some of the cost & $8(2.3)$ & I (2.5) & $6(2.9)$ & I (I.0) & \\
\hline
\end{tabular}

Abbreviations: HF, heart failure; NYHA, New York Heart Association.

caregivers $(>80 \%)$ reported that they did not pay directly for HF patients' medication, rehabilitation, or hospitalization costs. However, approximately $12 \%$ of caregivers reported that they paid for some or all of the travel cost for themselves and the patients (Table 3).

\section{Discussion}

Given that HF is a chronic condition associated with functional impairment, debilitating symptoms, complex medication, and self-care regimens, the daily (unpaid) support provided by family (informal) caregivers plays 
a major role in maintaining the health and QoL of approximately 40 million HF patients globally. ${ }^{1,6,7}$ However, in the area of HF research, patients have always been the focal point despite the importance of the caregiver role. ${ }^{9,10}$ Thus, it is imperative to understand the burden of these caregivers so that their needs can be addressed and their continued and effective support can be promoted.

This real-world cross-sectional study from Europe highlights that caregiver burden due to caring for patients with HF with LVEF $\leq 60 \%$ affects the caregivers' own health and QoL. Giving emotional support/encouragement to the patient, driving the patient to work/hospital/appointments, and reminding the patient to take medicine are the most troublesome/inconvenient activities to caregivers. HF caregiving responsibilities are associated with psychological problems such as stress and anxiety and impact the work of employed caregivers. It also demonstrates that caregiving burden is higher among the caregivers caring for patients with moderate to severe HF (NYHA class IIIIV) compared with those caring for patients with mild HF (NYHA class I or II).

In previous studies conducted on HF caregivers from the US, ${ }^{28}$ Europe, ${ }^{29}$ China, ${ }^{11}$ and Colombia, ${ }^{12}$ the caregivers were generally of mean age 55-69 years, females (60-84\%), and a family member of the patient (73-100\%). The caregiver profile for patients with HF in this study was consistent with that of previous studies and confirms the notion that the typical HF caregiver is an older female and a family member (most commonly the spouse) of the patient. Caregivers invest a considerable amount of their time for caring patients with HF. In this study, caregivers had been caring patients with HF for 3-4 years, and they spent on average 20 hours/week in caregiving activities. This corresponds to over 3000 hours over 3 years. The average amount of time spent weekly on HF caregiving equated to more than half (53\%) of the average weekly working time (37 hours) in Europe, indicating that caring for patients with $\mathrm{HF}$ is on average equivalent to a part-time job. Of note, the weekly time spent was even higher for the patients in NYHA classes III-IV (26 hours/week), which easily becomes incompatible with the caregiver's job. Evidence suggests that more caregiving time and responsibilities are strongly associated with low perceived physical health, self-care, social support, depressive symptoms, and financial strain among caregivers. ${ }^{30}$

Caregivers commonly supported the patient emotionally, reminded patients to take medications, helped with shopping, and drove the patient to work/hospital/ appointments. These findings were consistent with those of earlier studies from China ${ }^{11}$ and Colombia ${ }^{12}$ that used the same DSPTM-HF methodology to assess the burden of caregivers of patients with HF (48-59\% in NYHA class II and $21-29 \%$ in classes III-IV). Notably, emotional support to the patient with HF was reported as the most common and most troublesome aspect of the caregiving responsibilities. Previous research suggested that caregivers felt responsible to help the patient with HF emotionally and help them with commonly experienced negative emotions, but also found it the most challenging task. ${ }^{31,32}$

One-third of the caregivers experienced stress or anxiety. The results are within the range reported in a review of 26 studies that found $6-64 \%$ of caregivers of patients with HF experienced depressive symptoms. ${ }^{10}$ A meta-analysis based on seven studies reported a high strain on HF caregivers who were caring for patients with the worst symptoms. ${ }^{9}$ Our results also showed a similar trend of a higher prevalence of distress (stress, anxiety) in caregivers of patients in NYHA classes III-IV than those caring for class I/II patients. Deteriorations in the caregivers' general and emotional health and time for social activities have been reported due to HF caregiving. ${ }^{32}$ Caregivers often neglect their own health because of their focus on caregiving. ${ }^{33}$ The higher prevalence of stress/anxiety reported by caregivers of patients with a higher NYHA classification may have been influenced by pre-existing diagnoses of these conditions; however, this hypothesis has not been validated in this study.

The FAMQOL scale used in this study is a specifically designed and validated instrument to measure the QoL of family caregivers for patients with HF. ${ }^{24,34}$ The overall mean FAMQOL score was 55.3, which was consistent with that reported earlier (58.7-61.5). ${ }^{24,34,35}$ The overall FAMQOL score appeared to decrease with an increase in the NYHA class from I (58.1) to III-IV (52.2), indicating worsening HRQoL. All three domains of HRQoL, including physical, emotional, and social, were poorer for caregivers of patients in NYHA classes III-IV HF versus I or II. These results were consistent with findings from a previous meta-analysis, which included studies with patients' symptom severity classified as per NYHA class and using different instruments for HRQoL measurement, reported that a higher caregiver strain was associated with worse patient symptoms. ${ }^{9}$

The mean utility score in the widely used EQ-5D instrument was 0.90 , with no considerable difference in scores by NYHA class, which was in contrast to the 
FAMQOL scores. Previous research validating the results between EQ-5D and HF-specific caregiver questionnaire also reported a discordance between the two instruments. ${ }^{36}$ In this study, the EQ-5D utility score for caregivers $(0.90)$ was high and in line with the scores of the general population $(0.86-0.92)^{37}$ rather than in line with previously reported caregiver utilities $(0.76-0.83) .^{29,35}$ This was somewhat surprising given the increased self-reported anxiety and depression and lower HRQoL in the FAMQOL measure. Although the EQ-5D is a standard measure of HRQoL, these findings suggest that for assessing caregivers' burden due to HF, EQ-5D may not provide a sufficiently sensitive representation of the impact on HRQoL.

HF caregiving responsibilities impacted the professional work of the caregivers. About one-tenth of the caregivers made changes to their employment in the last year owing to $\mathrm{HF}$ caregiving responsibilities, and a small number of caregivers also indicated a drop in their income. This is consistent with the study by Bangerter 2018 reporting that caregivers have difficulty in balancing caregiving activities with professional responsibilities. ${ }^{38}$ Regarding the economic implications of HF caregiving, the direct costs related to patients' medicine, hospitalization, or rehabilitation were mostly covered by the healthcare system of the country. However, there was an element of financial burden on caregivers in the form of paying the cost of travel for themselves and the patient and indirect costs due to work productivity loss or opting for changes in job responsibilities. An observational study from Spain reported that informal care contributed the most, ranging from $59 \%$ to $70 \%$ of the overall healthcare cost in patients with HF, with a significant difference in the costs for NYHA class III-IV versus class II. ${ }^{39}$

This study suggests that while assessing the impact of HF on society, the burden imposed on caregivers should also be accounted for and considered an essential component of the overall burden of HF among the community. Younger caregivers, female caregivers, and caregivers with existing physical and emotional health issues have been reported to be particularly vulnerable. ${ }^{40}$ The burden on caregivers further increases if the patient has had recurrent emergency admissions or has recently been discharged home. ${ }^{40}$ Impact on caregivers' well-being and productivity is important as the surge in ageing population will only increase this burden further. Addressing the needs of caregivers of patients with HF must also be considered as a part of holistic HF management.

Adelphi's DSPTM methodology is well established ${ }^{21-23}$ and has frequently been used in real-world cross-sectional surveys for different disease areas. However, there are certain limitations of this study. The sample of caregivers of patients with HF may not represent the overall caregivers of patients with HF. Given that consecutive 10 suitable patients with HF along with their caregivers who consult the physician were included, this may have led to inclusion of patients and caregivers who consulted physicians more often. The caregiver self-completion questionnaire was voluntary and only caregivers who attended the patient's consultation with the physician were invited to complete this form. Thus, the number of caregiver selfcompletion questionnaires was considerably lower than the number of physician completed patient-record forms. Caregivers who chose to complete the caregiver selfcompletion questionnaire may reflect a more motivated sub-population, and their characteristics may be different from the non-responders. The inevitable limitations associated with data collected from surveys, including recall bias, missing data, and over-reporting of surveyed events, apply to this study as well. As the distribution of caregivers was uneven across the countries, regional differences (such as Northern vs Southern Europe) in caregiver burden could not be studied, and further research is warranted. Furthermore, the study did not evaluate if differences in individual country's healthcare systems, such as available facilities and support networks, influenced the level of burden experienced by caregivers, and so this should be explored with further research.

\section{Conclusion}

In conclusion, this real-world study shows that caregivers of patients with $\mathrm{HF}$ and LVEF $\leq 60 \%$ experienced a significant burden and spent a considerable amount of time providing daily support to patients with HF, with disruption to daily life, work productivity, and experience of stress and anxiety. Patients with a more severe disease were older, more polymorbid, and had been diagnosed for longer. Caregivers of patients with more severe and symptomatic disease experienced a higher burden across several important aspects, including increased anxiety and depression and reduced HRQoL. This study highlights that the burden of HF goes beyond that on patients and healthcare system and has broader societal implications through the impact on patients' friends and family, especially those in 
the caregiver role. Effective management of $\mathrm{HF}$ with reduction of symptoms and hospitalizations for patients will help to alleviate the burden not only for the patients but also for their caregivers.

\section{Acknowledgments}

Raju Gautam and Lovneet Saini (employees of Novartis Healthcare Pvt. Ltd., Hyderabad, India) provided medical writing assistance for this manuscript. The abstract of this paper was presented at the European Society of Cardiology (ESC) Congress, August 29 - September 02, 2020 as a poster presentation with interim findings. The poster's abstract was published in "Poster Abstracts" in European Heart Journal 2020;41(Suppl 2): https://doi.org/10.1093/ehjci/ehaa946. 0978.

\section{Funding}

This work was supported by Novartis Pharma AG, Basel, Switzerland.

\section{Disclosure}

R. Lahoz, C. Proudfoot, A. F. Fonseca, E. Loefroth, S. Corda and R. Studer are employees of Novartis Pharma AG, Basel, Switzerland. J. Jackson and S. Cotton are employees of Adelphi Real World, Bollington, United Kingdom and were contracted by Novartis to conduct this study. The authors report no other conflicts of interest in this work.

\section{References}

1. Disease GBD, Injury I, Prevalence C. Global, regional, and national incidence, prevalence, and years lived with disability for 310 diseases and injuries, 1990-2015: a systematic analysis for the Global Burden of Disease Study 2015. Lancet. 2016;388(10053):1545-1602.

2. Westenbrink BD, Brugts JJ, McDonagh TA, Filippatos G, Ruschitzka F, van Laake LW. Heart failure specialization in Europe. Eur J Heart Fail. 2016;18(4):347-349. doi:10.1002/ejhf.506

3. Khavjou O, Phelps D, Leib A. Projections of cardiovascular disease prevalence and costs: 2015-2035. technical report. 2016. Available from: https://healthmetrics.heart.org/wp-content/uploads/2017/10/ Projections-of-Cardiovascular-Disease.pdf. Accessed May 3, 2021.

4. Broström A, Strömberg A, Dahlström U, Fridlund B. Sleep difficulties, daytime sleepiness, and health-related quality of life in patients with chronic heart failure. $J$ Cardiovasc Nurs. 2004;19(4):234-242. doi:10.1097/00005082-200407000-00003

5. Cowie MR, Anker SD, Cleland JGF, et al. Improving care for patients with acute heart failure: before, during and after hospitalization. ESC Heart Fail. 2014;1(2):110-145. doi:10.1002/ehf2.12021

6. Jeon YH, Kraus SG, Jowsey T, Glasgow NJ. The experience of living with chronic heart failure: a narrative review of qualitative studies. BMC Health Serv Res. 2010;10:77. doi:10.1186/1472-6963-10-77

7. Norberg EB, Boman K, Löfgren B. Activities of daily living for old persons in primary health care with chronic heart failure. Scand $J \quad$ Caring Sci. 2008;22(2):203-210. doi:10.1111/j.14716712.2007.00514.x
8. Saunders MM. Factors associated with caregiver burden in heart failure family caregivers. West J Nurs Res. 2008;30(8):943-959. doi:10.1177/0193945908319990

9. Bidwell JT, Lyons KS, Cs L. Caregiver well-being and patient outcomes in heart failure: a meta-analysis. J Cardiovasc Nurs. 2017;32 (4):372-382. doi:10.1097/JCN.0000000000000350

10. Lacerda MS, Do Prado PR, de Barros ALBL, de Lima Lopes J. Depressive symptoms in the family caregivers of patients with heart failure: an integrative review. Rev Gaucha Enferm. 2019;40. doi:10.1590/1983-1447.2019.20180057

11. Jackson JD, Cotton SE, Bruce Wirta S, et al. Burden of heart failure on caregivers in China: results from a cross-sectional survey. Drug Des Devel Ther. 2018;12:1669-1678. doi:10.2147/DDDT.S148970

12. Karpf E, Jackson J, Cotton S, et al. Assessing the burden of chronic heart failure on caregivers of patients in Colombia. Value Health. 2017;20(9):A622-A622. doi:10.1016/j.jval.2017.08.1358

13. Ponikowski P, Voors AA, Anker SD, et al. 2016 ESC guidelines for the diagnosis and treatment of acute and chronic heart failure: the task force for the diagnosis and treatment of acute and chronic heart failure of the European Society of Cardiology (ESC). Developed with the special contribution of the Heart Failure Association (HFA) of the ESC. Eur J Heart Fail. 2016;18(8):891-975. doi:10.1002/ejhf.592

14. Proudfoot C, Gogna S, Jindal R, Agrawal R, Laires PA. A review assessing the proportion of heart failure with preserved fraction patients amongst heart failure patients. Value Health. 2019;22:S557. doi:10.1016/j.jval.2019.09.811

15. Bloom MW, Greenberg B, Jaarsma T, et al. Heart failure with reduced ejection fraction. Nat Rev Dis Primers. 2017;3:17058. doi:10.1038/nrdp.2017.58

16. Yusuf S, Pfeffer MA, Swedberg K, et al. Effects of candesartan in patients with chronic heart failure and preserved left-ventricular ejection fraction: the CHARM-preserved trial. Lancet. 2003;362 (9386):777-781. doi:10.1016/S0140-6736(03)14285-7

17. Solomon SD, McMurray JJV, Anand IS, et al. Angiotensin-neprilysin inhibition in heart failure with preserved ejection fraction. NEJM. 2019;381(17):1609-1620. doi:10.1056/NEJMoa1908655

18. Lewis EF, Kim H-Y, Claggett B, et al. Impact of spironolactone on longitudinal changes in health-related quality of life in the treatment of preserved cardiac function heart failure with an aldosterone antagonist trial. Circ Heart Fail. 2016;9(3):e001937. doi:10.1161/ CIRCHEARTFAILURE.114.001937

19. Writing Committee M, Yancy CW, Jessup M, et al. 2013 ACCF/AHA guideline for the management of heart failure: a report of the American College of Cardiology Foundation/American Heart Association Task Force on practice guidelines. Circulation. 2013;128(16):e240-327. doi:10.1161/CIR.0b013e31829e8776

20. Rutledge T, Reis VA, Linke SE, Greenberg BH, Mills PJ. Depression in heart failure a meta-analytic review of prevalence, intervention effects, and associations with clinical outcomes. $\mathrm{J} \mathrm{Am} \mathrm{Coll} \mathrm{Cardiol.}$ 2006;48(8):1527-1537. doi:10.1016/j.jacc.2006.06.055

21. Anderson P, Benford M, Harris N, Karavali M, Piercy J. Real-world physician and patient behaviour across countries: disease-specific programmes-a means to understand. Curr Med Res Opin. 2008;24 (11):3063-3072. doi:10.1185/03007990802457040

22. Babineaux SM, Curtis B, Holbrook T, Milligan G, Piercy J. Evidence for validity of a national physician and patient-reported, cross-sectional survey in China and UK: the disease specific programme. BMJ Open. 2016;6(8):e010352. doi:10.1136/bmjopen2015-010352

23. Higgins V, Piercy J, Roughley A, et al. Trends in medication use in patients with type 2 diabetes mellitus: a long-term view of real-world treatment between 2000 and 2015. Diabetes Metab Syndr Obes. 2016;9:371-380. doi:10.2147/DMSO.S120101

24. Nauser JA, Bakas T, Welch JL. A new instrument to measure quality of life of heart failure family caregivers. J Cardiovasc Nurs. 2011;26 (1):53-64. doi:10.1097/JCN.0b013e3181e4a313 
25. Group TE. EuroQol-a new facility for the measurement of healthrelated quality of life. Health Policy. 1990;16(3):199-208. doi:10.1016/0168-8510(90)90421-9

26. Herdman M, Gudex C, Lloyd A, et al. Development and preliminary testing of the new five-level version of EQ-5D (EQ-5D-5L). Qual Life Res. 2011;20(10):1727-1736. doi:10.1007/s11136-011-9903-x

27. National Institute for Health and Care Excellence (NICE). Position statement on use of the EQ-5D-5L valuation set for England (updated October 2019). 2019. Available from: https://www.nice.org.uk/about/ what-we-do/our-programmes/nice-guidance/technology-appraisalguidance/eq-5d-51. Accessed September 15, 2020.

28. Ågren S, Evangelista L, Strömberg A. Do partners of patients with chronic heart failure experience caregiver burden? Eur J Cardiovasc Nurs. 2010;9(4):254-262. doi:10.1016/j.ejcnurse.2010.03.001

29. Iqbal J, Francis L, Reid J, Murray S, Denvir M. Quality of life in patients with chronic heart failure and their carers: a 3-year follow-up study assessing hospitalization and mortality. Eur J Heart Fail. 2010;12(9):1002-1008. doi:10.1093/eurjhf/hfq114

30. Nicholas Dionne-Odom J, Hooker SA, Bekelman D, et al. Family caregiving for persons with heart failure at the intersection of heart failure and palliative care: a state-of-the-science review. Heart Fail Rev. 2017;22(5):543-557. doi:10.1007/s10741-017-9597-4

31. Hwang B, Luttik ML, Dracup K, Jaarsma T. Family caregiving for patients with heart failure: types of care provided and gender differences. J Card Fail. 2010;16(5):398-403. doi:10.1016/j. cardfail.2009.12.019

32. Bakas T, Pressler SJ, Johnson EA, Nauser JA, Shaneyfelt T. Family caregiving in heart failure. Nurs Res. 2006;55(3):180-188. doi:10.1097/00006199-200605000-00004

33. Negarandeh R, Delkhosh M, Janani L, Samiei N, Ghasemi E. The relationship between perceived life changes and mental health in family caregivers of patients with heart failure who referred to Rajaei Cardiovascular Medical and Research Center, Tehran. Int J Community Based Nurs Midwifery. 2015;3(4):283.
34. Dulgeroglu C, Gurkan A. Reliability and validity of family caregiver quality of life scale in heart failure. Turk Gogus Kalp Damar. 2018;26(1):73-80. doi:10.5606/tgkdc.dergisi.2018.14998

35. Wingham J, Frost J, Britten N, et al. Caregiver outcomes of the REACH-HF multicentre randomized controlled trial of home-based rehabilitation for heart failure with reduced ejection fraction. Eur J Cardiovasc Nurs. 2019;18(7):611-620. doi:10.1177/ 1474515119850011

36. Stromberg A, Bonner N, Grant L, et al. Psychometric validation of the Heart Failure Caregiver Questionnaire (HF-CQ((R))). Patient. 2017;10(5):579-592. doi:10.1007/s40271-017-0228-X

37. Janssen MF, Szende A, Cabases J, Ramos-Goñi JM, Vilagut G, König HH. Population norms for the EQ-5D-3L: a cross-country analysis of population surveys for 20 countries. Eur J Health Econ. 2019;20(2):205-216. doi:10.1007/s10198-018-0955-5

38. Bangerter LR, Griffin JM, Dunlay SM. Qualitative study of challenges of caring for a person with heart failure. Geriatr Nurs. 2018;39(4):443-449. doi:10.1016/j.gerinurse.2017.12.017

39. Delgado JF, Oliva J, Llano M, et al. Health care and nonhealth care costs in the treatment of patients with symptomatic chronic heart failure in Spain. Rev Esp Cardiol. 2014;67(8):643-650. doi:10.1016/j.rec.2013.12.014

40. Whittingham K, Barnes S, Gardiner C. Tools to measure quality of life and carer burden in informal carers of heart failure patients: a narrative review. Palliat Med. 2013;27(7):596-607. doi:10.1177/ 0269216313477179
Patient Preference and Adherence

\section{Publish your work in this journal}

Patient Preference and Adherence is an international, peer-reviewed, open access journal that focusing on the growing importance of patient preference and adherence throughout the therapeutic continuum. Patient satisfaction, acceptability, quality of life, compliance, persistence and their role in developing new therapeutic modalities and compounds to optimize clinical outcomes for existing disease

\section{Dovepress}

states are major areas of interest for the journal. This journal has been accepted for indexing on PubMed Central. The manuscript management system is completely online and includes a very quick and fair peer-review system, which is all easy to use. Visit http:// www.dovepress.com/testimonials.php to read real quotes from published authors. 